\title{
The fatty acid composition of the Longissimus dorsi muscle, subcutaneous and visceral fats differ in four commercial pig breeds*
}

\author{
D. Klensporf-Pawlik ${ }^{1}$, M. Szydlowski² ${ }^{2}$ A. Kaczmarek ${ }^{1}$, \\ J. Nowacka-Woszuk ${ }^{2}$, M. Switonski ${ }^{2}$ and H. Jeleń ${ }^{1,3}$ \\ Poznan University of Life Sciences, \\ ${ }^{1}$ Faculty of Food Science and Nutrition, \\ ${ }^{2}$ Department of Genetics and Animal Breeding \\ Wotyńska 33, 60-637 Poznań, Poland
}

(Received 26 April 2012; revised version 20 October 2012; accepted 15 November 2012)

\begin{abstract}
Fatness traits, including fatty acid (FA) composition, influence the dietary value of meat products. In this study we compared the fatty acid profiles in the carcasses of two main Polish breeds, Polish Large White (PLW) and Polish Landrace (PL), and two common commercial ones, Duroc and Pietrain. The Longissimus dorsi muscle, subcutaneous and visceral fats were sampled from 85 gilts that were fed the same diets and slaughtered at the same body weight (100 kg). Several significant between-breed differences were observed in FA composition, especially in subcutaneous and abdominal fat. In all tissues, the lowest percentage of saturated fatty acids (SFA) was observed in Pietrain pigs, with the differences depending mainly on C16:0 and C18:0. In abdominal fat, the highest content of monounsaturated fatty acids was found in that of PLW, chiefly due to an elevated content of C18:1 n-9. In both adipose tissues the highest content of polyunsaturated fatty acids (PUFA) was found in Pietrain and the lowest in PLW. These differences were mainly because of the high content of C18:2 in Pietrain pigs. The existence of between-breed and tissue differences was confirmed by linear discriminant analysis, which revealed that the studied tissues can be distinguished according to FA profile with an overall prediction ability of $89.8 \%$. It was also shown that the percentage of PUFA in the studied tissues was negatively correlated with abdominal fat weight. We conclude that the FA profile in the carcass of Pietrain pigs is the most favourable, while two Polish breeds and the Duroc breed have similar FA profiles.
\end{abstract}

KEY WORDS: fatty acids, fatness, intramuscular fat, abdominal fat, Longissimus dorsi muscle, pigs

\footnotetext{
* Supported by the Polish Ministry of Science and Higher Education, Grant No. N311 288936

${ }^{3}$ Corresponding author: e-mail: henrykj@up.poznan.pl
} 


\section{INTRODUCTION}

Adipose tissue, an important endocrine organ and reservoir of energy, is accumulated mainly as subcutaneous backfat (BF) and visceral fat (abdominal fat, AF). Fat deposed in skeletal muscle as intramuscular fat (IMF) is important for meat quality, however. The amount and distribution of IMF and its fatty acid composition influence sensory quality, as well as the dietary value of meat (Wood et al., 2008). On the other hand, BF and AF depots are also important since they are used in meat processing. Both IMF content and its fatty acid composition are considered to be quantitative traits, thus their phenotypic variability depends on genetic and environmental factors. The genetic background of porcine fatness traits has been studied extensively and to date a large number of candidate genes contributing to the phenotypic variability of these traits, as well as detection of QTL (quantitative trait locus), has been reported (Switonski et al., 2010).

It is known that the composition of fatty acids in the carcass of pigs can be modified by feeding (Kouba and Maurot, 2011), while the heritability coefficients $\left(\mathrm{h}^{2}\right)$ for fatty acid content in pig carcass oscillate around 0.5 (Ntawubiziet al., 2010; Sellier et al., 2010). Therefore, searching for genetic variance of the phenotype variability of fatty acid composition in pig carcasses has become an important goal for the pig breeding industry. The detection of QTL regions for fatty acid composition has been reported several times, and a recent genome-wide association study (GWAS) in Duroc pigs revealed several QTL for FA composition of IMF and BF (Uemoto et al., 2012). Apart from genome scanning, polymorphism analyses of selected positional or functional candidate genes for carcass FA composition have also been carried out. An example is a study of the FABP3 ( $H$-FABP) gene, for which polymorphism analysis showed an association with the n-6 PUFA content in the IMF of the Longissimus dorsi muscle (Lee et al., 2010).

Since the fatty acid composition in the porcine carcass is a heritable quantitative trait, it is not surprising that breed-specific variability of the fatty acid profile in pig tissues has been observed. It is well known that the content of unsaturated FA in backfat tissue of Pietrain pigs is higher than in Large White pigs (Wood and Lister, 1973). Comparison of the FA profile in backfat, perirenal fat, and Longissimus dorsi muscle in the Large White and Landrace breeds revealed that the monounsaturated fatty acids (MUFA) content was higher in all of these tissues in Landrace (Sellier et al., 2010). The composition of fatty acids in IMF was also studied at three slaughter weights $(90,110$, and $130 \mathrm{~kg})$ in four breeds (Pietrain, Duroc, Hampshire, and Belgian Landrace) and significant betweenbreed differences were described in Longissimus dorsi and backfat (Raj et al., 2010). In both tissues, the average (for three slaughter weights) SFA content was the lowest in Pietrain pigs, while the PUFA content was the highest, and that of MUFA was the lowest in this breed. 
Fatty acid composition is not uniform across all muscle tissues, as has been shown by comparison of Gluteus medius, Longissimus thoracis and Lumborum muscles in Duroc pigs (Quintanilla et al., 2011) or even in different layers of ham, loin, backfat, and abdominal fat (Monziols et al., 2007). Thus, conclusions drawn for a specific tissue cannot be directly extrapolated to the others.

Until now, studies on fatty acid composition in pig carcasses were done mainly for the most important commercial breeds (Large White, Landrace, Duroc, Pietrain and Hamshire) or crosses. There is also a report in which two main Polish breeds (Polish Large White and Polish Landrace), considered the maternal component for commercial crosses, were compared with Pietrain and Duroc breeds and the 990 synthetic line in terms of the FA profile in Longissimus dorsi (Mieńkowska-Stępniewska et al., 2006). In our study, we also used gilts of the same breeds, maintained under the same environmental conditions (the same Pig Testing Station), fed with the same feeds, and slaughtered at the same body weight $(100 \mathrm{~kg})$. The aim of this study was to compare the FA profiles in the carcasses of pigs representing four breeds (Polish Large White, Polish Landrace, Pietrain, and Duroc), in three tissues: Longissimus dorsi and two adipose tissues, subcutaneous fat and abdominal fat. We also explored the applicability of discriminat analysis to differentiate the studied tissues in these breeds based of their FA profile.

\section{MATERIAL AND METHODS}

\section{Animals and tissues}

Altogether, 85 unrelated gilts, representing four breeds (Pietrain-17, Duroc-23, Polish Large White, PLW-23 and Polish Landrace, PL-22), were studied. All animals were individually fed ad libitum with a commercial mix feeds in a local Pig Testing Station, slaughtered at $100 \mathrm{~kg}$ body weight and dissected. Two diets were used, according to body weight: diet I (30-80 kg) contained 13.5 MJ of metabolizable energy, $18.5 \%$ of crude protein, $5 \%$ of crude fat and $3.5 \%$ of crude fibre, and diet II (80-100 kg) contained: $13.0 \mathrm{MJ}, 17.0 \%, 4.0 \%$ and $4.0 \%$, respectively. The same feeding allowed us to exclude the effect of fatty acid intake on fatty acids composition in the studied tissues and breeds.

At slaughter three fatness traits were recorded: intramuscular fat content (\%), backfat thickness (cm, average from 5 points) and abdominal fat weight (kg). The following tissue samples were collected: Longissimus dorsi muscle (LM), subcutaneous fat (SF) at the $10^{\text {th }}$ vertebra, and perirenal abdominal fat (AF). The samples were deep frozen and stored in $-20^{\circ} \mathrm{C}$ until analysis. 
Fatty acid analysis

Samples of LM, SF and AF were homogenized and total lipids were extracted using a chloroform-methanol 2:1 (v/v) according to Folch et al. (1957). Fatty acids methyl esters were prepared by esterification with sodium methoxide: extracted lipids were dried in a glass vial under a stream of nitrogen and dissolved in $1 \mathrm{ml}$ of hexane, then $1 \mathrm{ml}$ of $0.4 \mathrm{~N} \mathrm{CH}_{3} \mathrm{ONa}$ was added, the mixture was shaken in a vortex for $1 \mathrm{~min}$. and left at room temperature for $20 \mathrm{~min}$. After that time $1 \mathrm{ml}$ of water was added and the upper (hexane) layer was transferred to the $1.8 \mathrm{ml}$ autosampler vial. A Hewlett Packard HP 6890 gas chromatograph, equipped with the Supelcowax-10 capillary column (30 m x 0.32 $\mathrm{mm} \times 0.25 \mathrm{um}$ ) and a flame ionization detector was used to separate the fatty acids methyl esters. Hydrogen was used as the carrier gas. The injection port and detector was set to $250^{\circ} \mathrm{C}$. The oven temperature programme was $80^{\circ} \mathrm{C}$, followed by an increase of $12^{\circ} \mathrm{C} / \mathrm{min}$ to $210^{\circ} \mathrm{C}$ held for $10 \mathrm{~min}$. Individual fatty acids were identified in comparison with the commercially available standards (Supelco, Bellefonte, PA). Fatty acid composition was expressed as a weight percentage of total fatty acids. All analyses were carried out in triplicates.

\section{Statistical analysis}

The records for each fatty acid content (in \%) were checked for outliers, using Hotelling's $\mathrm{T}^{2}$-statistics before further analysis.

The atherogenicity index was calculated as:

$$
(\mathrm{C} 12: 0+4 \times \mathrm{C} 14: 0+\mathrm{C} 16: 0) /(\mathrm{MUFA}+\mathrm{PUFA}) \backslash
$$

and the thrombogenicity index as:

$$
\begin{gathered}
(\mathrm{C} 14: 0+\mathrm{C} 16: 0+\mathrm{C} 18: 0) /(0.5 \times \text { MUFA }+0.5 \times \mathrm{n}-6 \mathrm{PUFA}+3 \times \mathrm{n}-3 \text { PUFA } \\
+(\mathrm{n}-3 \text { PUFA } / \mathrm{n}-6 \text { PUFA }))
\end{gathered}
$$

according to Ulbricht and Southgate (1991).

To explore the effect of breed on fatty acid profile, MUFA, PUFA and SFA and atherogenicity and thrombogenicity indices we used univariate linear models. The following mixed model (1) was used to estimate the variance contributed by breed effect:

$$
\mathrm{Y}_{\mathrm{ijk}}=\mathrm{T}_{\mathrm{i}}+\mathrm{B}_{\mathrm{ij}}+\mathrm{E}_{\mathrm{ijk}}
$$

where: $Y_{i j k}-$ the corrected phenotype; $T_{i}$ - the fixed effect of $i-t h$ tissue; $\mathrm{B}_{\mathrm{ij}}$ - nested random effect of $\mathrm{j}$-th breed with variance $\sigma_{B i}^{2}$ and $\mathrm{E}_{\mathrm{ijk}}$ - the residual effect with variance $\sigma_{e}^{2}$. 
The REML estimates for the variance components were calculated with Imer function (package Imer4 for $R$ ). The fraction of breed variance was calculated for each tissue as $100 \% \times \sigma_{B i}^{2} /\left(\sigma_{B i}^{2}+\sigma_{e}^{2}\right)$.

The tissue-by-breed interaction was tested under the following fixed model (2):

$$
\mathrm{Y}_{\mathrm{ijk}}=\mathrm{T}_{\mathrm{i}}+\mathrm{B}_{\mathrm{j}}+\mathrm{TB}_{\mathrm{ij}}+\mathrm{E}_{\mathrm{ijk} .}
$$

The four breeds were compared within each tissue separately under the fixed model (3):

$$
\mathrm{Y}_{\mathrm{ij}}=\mathrm{B}_{\mathrm{i}}+\mathrm{E}_{\mathrm{ij}} \text {. }
$$

A post-hoc test (Tukey's) was used to determine differences in means, where applicable.

We also checked whether breed effect, even if not significant for a particular fatty acid, is represented collectively in the fatty acid profile and whether the profile is breed/tissue-specific. For this we used Linear Discriminant Analysis (LDA, Statistica 8.0 StatSoft, Tulsa, USA).

The Pearson correlation coefficients between fatty acid levels were calculated after adjusting for the effect of breed. The estimates of breed effects were obtained from model (3). The t-statistic was used to test the correlation coefficients against the null hypothesis that the true correlation is zero.

\section{RESULTS}

\section{Carcass fatness}

The mean values of three fatness traits were as follows: IMF in \%: 1.56 (Duroc), 1.54 (Pietrain), 1.33 (PLW), and 1.51 (PL); BFT in cm:1.66 (Duroc), 1.24 (Pietrain), 1.63 (PLW), and 1.61 (PL), and AF in kg: 0.55 (Duroc), 0.36 (Pietrain), 0.59 (PLW), and 0.56 (PL). In the cases of BFT and AF the means were significantly lower $(\mathrm{P}<0.001)$ in Pietrain pigs in comparison with all of the others.

\section{Fatty acid composition}

The studied gilts were relatively homogeneous with respect to SFA and MUFA contents, which were the major fractions of fatty acids in the three examined tissues (Tables 1, 2 and 3). The coefficients of variation were low for SFA $(6.1 \%, 7.3 \%$ and $6.9 \%$ for Longissmus dorsi, subcutaneous and abdominal tissue, respectively), MUFA $(7.6 \% 6.9 \%, 8.3 \%)$, and relatively high for PUFA $(21.1 \%, 16.2 \%, 25.0 \%)$. 
Comparison of the studied breeds showed that the SFA content was the lowest in all three tissues of Pietrain pigs. Differences in MUFA and PUFA contents in Longissmus dorsi were insignificant. In backfat, the highest MUFA content was found in PLW and the lowest in Duroc, while the PUFA content was the highest in Pietrain and the lowest in PLW. Finally, in abdominal fat the MUFA content was the highest in PLW and the lowest in Duroc. The PUFA content in this tissue, similarly to backfat, was the highest in Pietrain and the lowest in PLW.

Table 1. Fatty acid composition (\% of total fatty acids) in Longissimus dorsi muscle. Saturated fatty acids (SFA), monounsaturated fatty acids (MUFA), polyunsaturated fatty acids (PUFA), atherogenicity index (AI) and thrombogenicity index (TI)

\begin{tabular}{|c|c|c|c|c|c|c|c|c|}
\hline \multirow[t]{2}{*}{ Indices } & \multicolumn{2}{|c|}{ Duroc } & \multicolumn{2}{|c|}{ Pietrain } & \multicolumn{2}{|c|}{$\begin{array}{c}\text { Polish Large } \\
\text { White }\end{array}$} & \multicolumn{2}{|c|}{$\begin{array}{c}\text { Polish } \\
\text { Landrace }\end{array}$} \\
\hline & mean & SD & mean & SD & mean & $\mathrm{SD}$ & mean & SD \\
\hline$\overline{\mathrm{C} 14: 0}$ & $1.46^{\mathrm{a}}$ & 0.13 & $1.37^{\mathrm{b}}$ & 0.15 & $1.29^{c}$ & 0.14 & $1.25^{c}$ & 0.17 \\
\hline C16:0 & $24.90^{\mathrm{a}}$ & 0.79 & $24.09^{\mathrm{b}}$ & 1.00 & $24.14^{\mathrm{b}}$ & 1.19 & $24.69^{\mathrm{a}}$ & 0.97 \\
\hline C16:1 & $2.85^{\mathrm{a}}$ & 0.42 & $2.94^{\mathrm{a}}$ & 0.44 & $2.57^{\mathrm{b}}$ & 0.56 & $2.34^{c}$ & 0.32 \\
\hline C17:0 & $0.34^{\mathrm{a}}$ & 0.11 & $0.27^{\mathrm{b}}$ & 0.06 & $0.31^{\mathrm{ab}}$ & 0.07 & $0.32^{\mathrm{ab}}$ & 0.09 \\
\hline C17:1 & $0.30^{\mathrm{a}}$ & 0.07 & $0.26^{\mathrm{a}}$ & 0.08 & $0.29^{\mathrm{a}}$ & 0.09 & $0.26^{\mathrm{a}}$ & 0.06 \\
\hline C18:0 & $14.10^{\mathrm{a}}$ & 1.42 & $13.21^{\mathrm{b}}$ & 1.03 & $13.99^{a}$ & 2.14 & $14.32^{\mathrm{a}}$ & 0.92 \\
\hline C18:1n-9 & $40.09^{\mathrm{a}}$ & 2.33 & $39.89^{a}$ & 2.32 & $40.03^{\mathrm{a}}$ & 3.73 & $39.08^{a}$ & 2.58 \\
\hline C18:1n-7 & $3.67^{\mathrm{ab}}$ & 0.42 & $3.89^{\mathrm{a}}$ & 0.41 & $3.61^{\mathrm{b}}$ & 0.54 & $3.20^{c}$ & 0.56 \\
\hline C18:2n-6 & $9.99^{\mathrm{b}}$ & 1.91 & $11.37^{\mathrm{a}}$ & 2.42 & $10.73^{\mathrm{ab}}$ & 2.53 & $10.63^{\mathrm{ab}}$ & 2.26 \\
\hline C18:3n-3 & $0.76^{\mathrm{d}}$ & 0.13 & $1.00^{c}$ & 0.42 & $1.23^{\mathrm{b}}$ & 0.38 & $1.99^{\mathrm{a}}$ & 0.58 \\
\hline C20:0 & $0.33^{\mathrm{a}}$ & 0.22 & $0.36^{a}$ & 0.23 & $0.43^{\mathrm{a}}$ & 0.16 & $0.39^{\mathrm{a}}$ & 0.19 \\
\hline Others $^{1}$ & \multicolumn{2}{|c|}{1.21} & \multicolumn{2}{|c|}{1.35} & \multicolumn{2}{|c|}{1.38} & \multicolumn{2}{|c|}{1.53} \\
\hline SFA & $41.04^{\mathrm{D}}$ & 2.13 & $39.15^{\mathrm{a}}$ & 1.90 & $40.06^{\mathrm{aD}}$ & 3.05 & $41.23^{\mathrm{b}}$ & 1.52 \\
\hline MUFA & $46.91^{\mathrm{D}}$ & 2.90 & $46.98^{\mathrm{D}}$ & 2.71 & $46.50^{\mathrm{D}}$ & 4.39 & $44.88^{\mathrm{a}}$ & 3.05 \\
\hline PUFA & $10.75^{\mathrm{a}}$ & 1.99 & $12.37^{\mathrm{D}}$ & 2.60 & $11.96^{\mathrm{D}}$ & 2.63 & $12.62^{\mathrm{D}}$ & 2.46 \\
\hline AI & 0.52 & 0.029 & 0.49 & 0.036 & 0.50 & 0.047 & 0.52 & 0.041 \\
\hline TI & $1.30^{\mathrm{A}}$ & 0.106 & $1.19^{\mathrm{B}}$ & 0.109 & $1.19^{\mathrm{B}}$ & 0.129 & $1.19^{\mathrm{B}}$ & 0.084 \\
\hline
\end{tabular}

${ }^{1}$ others - identified fatty acids, percentage low (C20:1; C20:2; C20:4); ${ }^{\text {a,b,c }}$ within a row, means with a different superscript are significantly different: small letter $(\mathrm{P}<0.05)$, capital letter $(\mathrm{P}<0.01)$

The limited variability of the fatty acid fraction translated into low variability in the atherogenicity index (AI) $(\mathrm{CV}: 8.4 \%, 9.5 \%, 10.0 \%)$ and moderate variability of the thrombogenicity index (TI) (CV: $10.4 \%, 13.2 \% 15.0 \%)$. Only a small proportion of the variance of SFA, MUFA, and PUFA contents in Longissmus dorsi tissue was contributed by the effect of breed $(9.7 \%, 7.9 \%, 7.7 \%$, respectively). Nonetheless, the breeds differed in fatty acid profiles in the two fat tissues. In subcutaneous fat, the percentage of the total variance due to breed was $42.0 \%, 9.9 \%$, and $31.4 \%$ for SFA, MUFA, and PUFA, respectively. In abdominal tissue, these proportions were even higher: $45.5 \%, 12.9 \%$, and $37.1 \%$. In Longissimus dorsi, the breed effect contributed only $8.1 \%$ of the total variance of the atherogenicity index and $10.0 \%$ of the thrombogenicity index, whereas the corresponding contributions were much higher in subcutaneous tissue $(31.7 \%$ and $32.8 \%$, respectively) and abdominal fat ( $45.0 \%$ and $55.9 \%)$. 
Table 2. Fatty acid composition (\% of total fatty acids) in subcutaneous fat of investigated pigs. Saturated fatty acids (SFA), monounsaturated fatty acids (MUFA), polyunsaturated fatty acids (PUFA), atherogenicity index (AI) and thrombogenicity index (TI)

\begin{tabular}{|c|c|c|c|c|c|c|c|c|}
\hline \multirow{2}{*}{ Indices } & \multicolumn{2}{|c|}{ Duroc } & \multicolumn{2}{|c|}{ Pietrain } & \multicolumn{2}{|c|}{$\begin{array}{l}\text { Polish Large } \\
\text { White }\end{array}$} & \multicolumn{2}{|c|}{ Polish Large } \\
\hline & mean & SD & mean & SD & mean & SD & mean & SD \\
\hline C14:0 & $1.29^{\mathrm{a}}$ & 0.09 & $1.17^{\mathrm{b}}$ & 0.07 & $1.21^{\mathrm{b}}$ & 0.11 & $1.19^{\mathrm{b}}$ & 0.12 \\
\hline C16:0 & $24.83^{\mathrm{a}}$ & 0.91 & $23.07^{\mathrm{b}}$ & 1.55 & $24.71^{\mathrm{a}}$ & 0.97 & $24.54^{\mathrm{a}}$ & 1.08 \\
\hline C16:1 & $1.62^{\mathrm{b}}$ & 0.25 & $1.88^{\mathrm{a}}$ & 0.35 & $1.73^{\mathrm{b}}$ & 0.37 & $1.61^{\mathrm{b}}$ & 0.20 \\
\hline C17:0 & $0.43^{\mathrm{a}}$ & 0.07 & $0.32^{c}$ & 0.07 & $0.38^{\mathrm{b}}$ & 0.09 & $0.34^{c}$ & 0.08 \\
\hline C17:1 & $0.33^{c}$ & 0.07 & $0.29^{b c}$ & 0.07 & $0.31^{\mathrm{ab}}$ & 0.07 & $0.27^{\mathrm{c}}$ & 0.06 \\
\hline C18:0 & $16.16^{\mathrm{a}}$ & 1.54 & $13.32^{\mathrm{b}}$ & 2.00 & $15.92^{\mathrm{a}}$ & 2.23 & $16.08^{\mathrm{a}}$ & 1.20 \\
\hline C18:1 n-9 & $35.43^{\mathrm{b}}$ & 2.46 & $37.05^{\mathrm{a}}$ & 2.80 & $37.68^{\mathrm{a}}$ & 1.93 & $36.78^{a}$ & 1.98 \\
\hline C18:1 n-7 & $2.20^{\mathrm{b}}$ & 0.25 & $2.54^{\mathrm{a}}$ & 0.34 & $2.23^{b}$ & 0.40 & $2.11^{\mathrm{b}}$ & 0.24 \\
\hline C18:2 n-6 & $14.47^{\mathrm{b}}$ & 1.96 & $16.51^{\mathrm{a}}$ & 2.48 & $12.03^{c}$ & 1.74 & $11.98^{c}$ & 1.51 \\
\hline C18:3 n-3 & $1.27^{\mathrm{c}}$ & 0.19 & $1.54^{\mathrm{c}}$ & 0.65 & $1.85^{\mathrm{b}}$ & 0.72 & $3.01^{\mathrm{a}}$ & 0.71 \\
\hline C20:0 & 0.27 & 0.06 & 0.27 & 0.07 & 0.27 & 0.06 & 0.29 & 0.05 \\
\hline Others $^{1}$ & \multicolumn{2}{|c|}{1.72} & \multicolumn{2}{|c|}{2.05} & \multicolumn{2}{|c|}{1.69} & \multicolumn{2}{|c|}{1.79} \\
\hline SFA & $42.97^{\mathrm{B}}$ & 2.07 & $38.15^{\mathrm{A}}$ & 3.45 & $42.48^{\mathrm{B}}$ & 2.51 & $42.44^{\mathrm{B}}$ & 1.92 \\
\hline MUFA & $39.57^{\mathrm{a}}$ & 2.79 & 41.76 & 3.31 & $41.95^{\mathrm{b}}$ & 2.48 & 40.78 & 2.19 \\
\hline PUFA & $15.74^{\mathrm{B}}$ & 2.13 & $18.05^{\mathrm{A}}$ & 2.64 & $13.88^{\mathrm{B}}$ & 2.11 & $14.99^{\mathrm{B}}$ & 1.76 \\
\hline AI & $0.54^{\mathrm{B}}$ & 0.036 & $0.47^{\mathrm{A}}$ & 0.055 & $0.52^{\mathrm{B}}$ & 0.035 & $0.52^{\mathrm{B}}$ & 0.039 \\
\hline TI & $1.35^{\mathrm{A}}$ & 0.114 & $1.13^{\mathrm{B}}$ & 0.174 & $1.27^{\mathrm{C}}$ & 0.147 & $1.16^{\mathrm{B}}$ & 0.092 \\
\hline
\end{tabular}

${ }^{1}$ others - identified fatty acids, percentage low (C20:1; C20:2; C20:4); ${ }^{\text {a,b,c }}$ within a row, means with a different superscript are significantly different: small letter $(\mathrm{P}<0.05)$, capital letter $(\mathrm{P}<0.01)$

The tissue-by-breed interaction appeared to be significant for C16:1, C18:0, C18:1 n-7 $(\mathrm{P}<0.05)$ and $\mathrm{C} 18: 2 \mathrm{n}-6(\mathrm{P}<0.001)$. The interaction was, however, always significant when we analysed any fatty acid fraction (SFA, MUFA, PUFA) or index (atherogenicity and thrombogenicity). Therefore, the four represented breeds were compared within each tissue separately.

The fatty acid composition analysed by breed within the Longissimus dorsi muscle, subcutaneous and abdominal fat is shown in Tables 1, 2 and 3, respectively. On comparing the main groups of fatty acids (SFA, MUFA, PUFA) for the three investigated tissues, the highest relative contents of saturated fatty acids were found for abdominal fat, followed by the contents in subcutaneous fat and Longissimus dorsi muscle. The percentage of monounsaturated fatty acids was the highest in intramuscular fat, followed by subcutaneous fat and abdominal fat. Polyunsaturated fatty acids formed the largest group of fatty acids in subcutaneous fat, followed by abdominal and intramuscular fat.

In Longissimus dorsi (intramuscular fat), the breed effect on fatty acid composition was smaller than in backfat and visceral fat. There were no betweenbreed differences in terms of SFA, MUFA, or PUFA contents. Some significant differences for specific fatty acids were found, however. The biggest difference was observed in the concentration of saturated fatty acids such as C14:0, C16:0, $\mathrm{C} 18: 0$, and a polyunsaturated fatty acid, C18:3 n-3. Duroc pigs showed a 
Table 3. Fatty acid composition (\% of total fatty acids) in abdominal fat of investigated pigs. Saturated fatty acids (SFA), monounsaturated fatty acids (MUFA), polyunsaturated fatty acids (PUFA), atherogenicity index (AI) and thrombogenicity index (TI)

\begin{tabular}{|c|c|c|c|c|c|c|c|c|}
\hline \multirow[t]{2}{*}{ Indices } & \multicolumn{2}{|c|}{ Duroc } & \multicolumn{2}{|c|}{ Pietrain } & \multicolumn{2}{|c|}{$\begin{array}{c}\text { Polish Large } \\
\text { White }\end{array}$} & \multicolumn{2}{|c|}{ Polish Landrace } \\
\hline & mean & SD & mean & SD & mean & SD & mean & SD \\
\hline$\overline{\mathrm{C} 14: 0}$ & $1.51^{\mathrm{a}}$ & 0.13 & $1.45^{\mathrm{a}}$ & 0.11 & $1.37^{\mathrm{b}}$ & 0.13 & $1.35^{\mathrm{b}}$ & 0.11 \\
\hline C16:0 & $27.62^{\mathrm{a}}$ & 0.73 & $26.24^{c}$ & 1.25 & $27.13^{\mathrm{b}}$ & 1.15 & $26.93^{b}$ & 0.88 \\
\hline C16:1 & $1.51^{\mathrm{c}}$ & 0.29 & $1.82^{\mathrm{a}}$ & 0.39 & $1.66^{\mathrm{b}}$ & 0.30 & $1.51^{\mathrm{c}}$ & 0.23 \\
\hline C17:0 & $0.38^{\mathrm{a}}$ & 0.07 & $0.31^{\mathrm{b}}$ & 0.08 & $0.34^{\mathrm{b}}$ & 0.10 & $0.33^{b}$ & 0.07 \\
\hline C17:1 & $0.25^{a}$ & 0.05 & $0.23^{\mathrm{ab}}$ & 0.06 & $0.24^{\mathrm{ab}}$ & 0.08 & $0.22^{\mathrm{b}}$ & 0.04 \\
\hline C18:0 & $20.99^{a}$ & 1.51 & $17.32^{c}$ & 1.67 & $20.03^{b}$ & 2.50 & $20.22^{\mathrm{ab}}$ & 2.06 \\
\hline C18:1 n-9 & $31.97^{c}$ & 2.73 & $33.33^{\mathrm{ab}}$ & 2.81 & $34.56^{\mathrm{a}}$ & 1.92 & $32.93^{\mathrm{bc}}$ & 2.74 \\
\hline C18:1 n-7 & $1.83^{c}$ & 0.26 & $2.23^{\mathrm{a}}$ & 0.29 & $2.01^{\mathrm{b}}$ & 0.28 & $1.85^{\mathrm{c}}$ & 0.24 \\
\hline C18:2 n-6 & $11.33^{\mathrm{b}}$ & 2.25 & $13.96^{\mathrm{a}}$ & 3.51 & $9.62^{c}$ & 2.37 & $10.37^{\mathrm{bc}}$ & 1.53 \\
\hline C18:3 n-3 & $1.05^{c}$ & 0.20 & $1.37^{\mathrm{b}}$ & 0.55 & $1.51^{\mathrm{b}}$ & 0.57 & $2.60^{\mathrm{a}}$ & 0.64 \\
\hline $20: 0$ & $0.30^{\mathrm{ab}}$ & 0.05 & $0.30^{\mathrm{ab}}$ & 0.08 & $0.28^{b}$ & 0.06 & $0.32^{\mathrm{a}}$ & 0.11 \\
\hline Others $^{1}$ & \multicolumn{2}{|c|}{1.26} & \multicolumn{2}{|c|}{1.45} & \multicolumn{2}{|c|}{1.26} & \multicolumn{2}{|c|}{1.37} \\
\hline SFA & $50.81^{\mathrm{B}}$ & 1.95 & $45.62^{\mathrm{A}}$ & 2.68 & $49.15^{\mathrm{B}}$ & 3.17 & $49.16^{\mathrm{B}}$ & 2.61 \\
\hline MUFA & $35.56^{a}$ & 3.13 & $37.60^{\mathrm{bc}}$ & 3.29 & $38.47^{c}$ & 2.23 & $36.51^{\mathrm{ab}}$ & 3.01 \\
\hline PUFA & $12.37^{\mathrm{B}}$ & 2.44 & $15.32^{\mathrm{A}}$ & 3.76 & $11.13^{\mathrm{B}}$ & 2.73 & $12.97^{\mathrm{B}}$ & 1.82 \\
\hline AI & $0.69^{\mathrm{B}}$ & 0.043 & $0.60^{\mathrm{A}}$ & 0.050 & $0.65^{\mathrm{B}}$ & 0.062 & $0.65^{\mathrm{B}}$ & 0.053 \\
\hline TI & $1.86^{\mathrm{A}}$ & 0.144 & $1.47^{\mathrm{B}}$ & 0.209 & $1.65^{\mathrm{B}}$ & 0.210 & $1.53^{\mathrm{B}}$ & 0.147 \\
\hline
\end{tabular}

${ }^{1}$ others - identified fatty acids, percentage low (C20:1; C20:2; C20:4); ${ }^{\text {a,b,c }}$ within a row, means with a different superscript are significantly different: small letter $(\mathrm{P}<0.05)$, capital letter $(\mathrm{P}<0.01)$

significantly $(\mathrm{P}<0.05)$ higher level of myristic acid, C14:0, than the other pigs. Additionally, Duroc and Polish Landrace had the highest content of palmitic acid, C16:0, whereas the content of oleic acid, C18:1 n-9, was the lowest in Pietrain pigs.

The fatty acid composition of the subcutaneous fat was significantly influenced by breed. The most significant differences $(\mathrm{P}<0.05)$ were observed in the percentage of myristic (C14:0) and palmitic (C16:0) acids. The content of these acids was the highest in Duroc pigs. Additionally, the total level of polyunsaturated fatty acids in Pietrain pigs was much higher (18.05\%) than in other breeds.

The composition of fatty acids in visceral fat was also related to breed. Duroc pigs had the highest concentration of saturated fatty acids, namely myristic, palmitic, and margaric acids. Similarly to subcutaneous fat samples, Pietrain pigs had the highest concentration of total PUFA, mainly due to a high content of linoleic acid (13.96\%).

Classification of breeds and tissues based on fatty acid profiles using linear discriminat analysis

The purpose of this part of the study was to examine the possibility of using fatty acid composition within individual tissues for breed discrimination, as well as 
to explore the possibility of the use of fatty acid profiles for tissue differentiation. Discrimination of breeds based on fatty acid composition in the compared tissues is shown in Figure 1. In intramuscular fat, when fatty acids (C14:0-C20:1; $\mathrm{n}=182$ ) were analysed the greatest contribution to the first discriminant function was calculated for $\mathrm{C} 18: 3 \mathrm{n}-3$, and the second for C16:0. Polish Landrace is relatively well separated from the remaining breeds based on C18:3 n-3 contents in intramuscular fat (Figure 1A). In subcutaneous fat, $(\mathrm{C} 14: 0-\mathrm{C} 20: 2 ; \mathrm{n}=250)$, the fatty acids discriminating breeds to the highest extent were $\mathrm{C} 18: 3 \mathrm{n}-3 ; \mathrm{C} 17: 0$, $\mathrm{C} 20: 2 ; \mathrm{C} 14: 0$ and C16:0. The highest contributions to the first two discriminant functions were calculated for C18:3 n-3 and C17:0 (Figure 1B). In visceral fat (C14:0-C20:1; $\mathrm{n}=231)$, the most important fatty acids differentiating samples were C14:0, C18:3 n-3, C18:1 n-9, C17:0, and C18:0. For linear discriminant analysis, where a complete data matrix is required, variables C20:2 and C20:4 were not used (except C20:2 for subcutaneous fat), as in some samples these acids were below detection thresholds.

Prediction of breeds based on fatty acid composition varied depending on the breed and tissue. The breed prediction based on abdominal fat was $86 \%$ for Duroc, $83 \%$ for Pietrain, $82 \%$ for Polish Landrace, and $66.6 \%$ for Polish Large White. For subcutaneous fat, the corresponding values for these breeds were $84 \%, 91 \%, 87 \%$, and $67 \%$, respectively, while for intramuscular fat, the breed prediction abilities based on fatty acid profiles were $82 \%$ for Duroc, $33 \%$ for Pietrain, $78 \%$ for Polish Landrace, and 55\% for Polish Large White. The lowest breed prediction ability was observed for Polish Large White regardless of the fat origin.

One-way analysis of variance showed significant differences in FA within breeds in all analysed tissues. The discriminant analysis of tissues for all breeds is shown in Figure 2. The first discriminant function separated the intramuscular fat, whereas the second separated the subcutaneous fat. $\mathrm{Cis}$-vaccenic and palmitoleic acids were variables connected to the first function, whereas the second function was connected to palmitic and stearic acids. The overall prediction ability for the LDA model built for all breed samples was $89.76 \%$. Separately, for Polish Landrace the prediction of fat origin (IMF, AF, BF) based on the fatty acid profile was $92.02 \%$, whereas for the other breeds it was: $92.18 \%$ (Polish Large White), 95.24\% (Pietrain), and 100\% (Duroc).

Relation of fatty acids and fatness traits

We also studied the correlation between main fatness traits (IMF, BFT and AF) and fatty acid composition in the analysed tissues. An interesting finding was the detection of a negative correlation between abdominal fat weight and percentage 

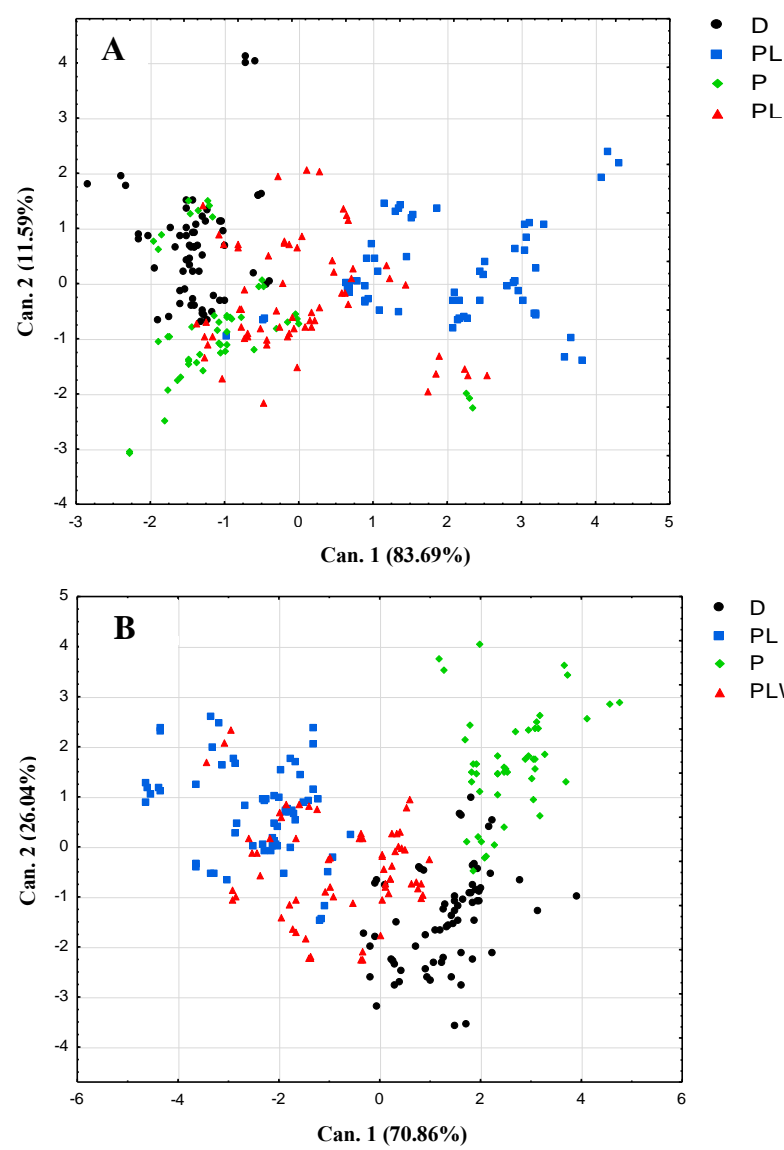

- D

- PL

- PLW

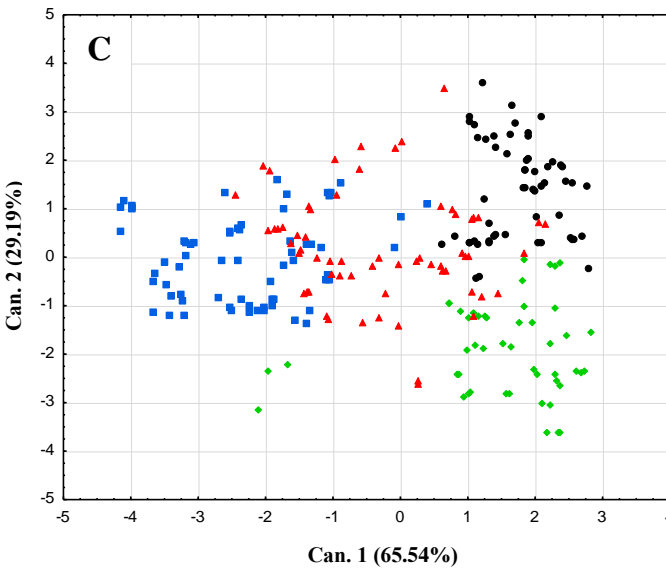

- $D$

- PL

- P

Figure 1. Discrimination of breeds based on the profiles of fatty acids; A - Longissimus dorsi muscle (IMF); B - subcutaneous fat (BF); C - abdominal fat (AF); D - Duroc; PL - Polish Landrace; P - Pietrain and PLW - Polish Large White 


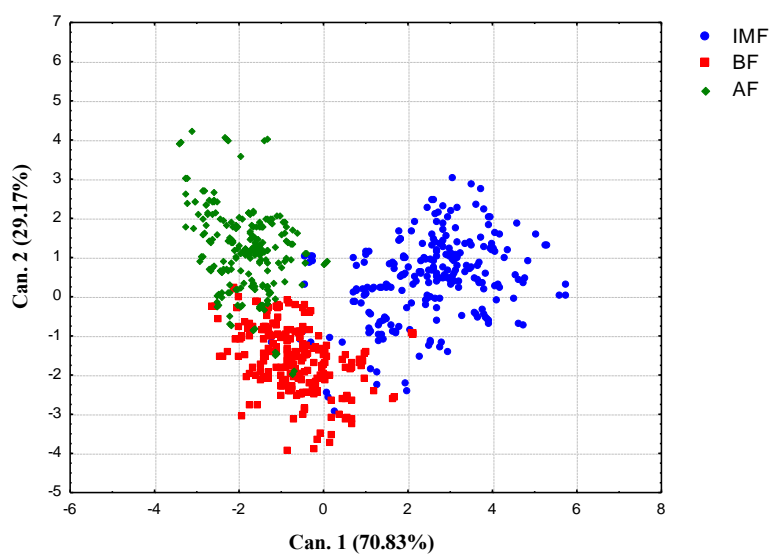

Figure 2. Linear discriminant analysis tissue classification, obtained from fatty acid composition data for all breeds investigated. IMF - intramuscular fat; BF - back (subcutaneous) fat; AF - abdominal (visceral) fat

of PUFA in the studied tissues of the analysed breeds (Table 4). This tendency was observed in all tissues and breeds. The highest Pearson correlations were: -0.54 (Longissimus dorsi of Duroc), -0.58 and -0.53 (backfat of Duroc and PL, respectively), -0.61 and -0.60 (abdominal fat of PLW and Duroc, respectively). The lowest correlations were calculated for Pietrain pigs: -0.16 (Longissimus dorsi), -0.08 (backfat) and 0.11 (abdominal fat).

Table 4. Correlation between abdominal fat weight and PUFA percentage in three examined tissues

\begin{tabular}{lcccc}
\hline \multirow{2}{*}{ Breed } & $\begin{array}{c}\text { Mean abdominal } \\
\text { fat weight, kg (SE) }\end{array}$ & $\begin{array}{c}\text { Longissimus } \\
\text { dorsi }\end{array}$ & $\begin{array}{c}\text { subcutaneous } \\
\text { fat }\end{array}$ & $\begin{array}{c}\text { abdominal } \\
\text { fat }\end{array}$ \\
\hline Duroc & $0.55(0.03)$ & -0.54 & -0.58 & -0.60 \\
Pietrain & $0.36(0.02)$ & -0.16 & -0.08 & 0.11 \\
PL & $0.56(0.02)$ & -0.17 & -0.53 & -0.27 \\
PLW & $0.59(0.03)$ & -0.33 & -0.39 & -0.61 \\
Across breeds & & -0.28 & -0.29 & -0.29 \\
\hline
\end{tabular}

\section{DISCUSSION}

In the nutritional trends to lower the intake of fat calories in the diet, the fatty acid composition of consumed fats has the same importance as calories consumed, especially in terms of energy intake from saturated fats and the polyunsaturatedto-saturated fatty acids (P:S) ratio (Wood et al., 2003). Apart from nutritional aspects, IMF influences meat tenderness and flavour, while the profile of fatty acids influences the colour and firmness of fat (Maw et al., 2003). For these reasons, the 
proper composition of fatty acids in meat and fat has become an important issue from the standpoint of consumers, nutritionists, and food technologists.

The manipulation of fatty acid composition in animal tissues is being explored mainly in feeding system studies. For instance, it is known that inclusion of linseed in diets for pigs (Corino et al., 2008) and sheep (Niedźwiedzka et al., 2008) improves the fatty acid profile of their tissues. It is also known that gender and castration, as well as weight at slaughter influence the fatty acid profile in pig tissues (Zhang et al., 2007; Peinado et al., 2012). On the other hand, studies on the genetic variability of fatty acid profiles in tissues of livestock, including the pig, are quite limited.

The fatty acid composition of subcutaneous fat was significantly influenced by breed. Our study showed that the FA profile in carcasses of Pietrain pigs is exceptional in terms of the lowest content of SFA and the highest of PUFA. This observation confirms earlier reports (e.g.,Wood and Lister, 1973; MieńkowskaStępniewska et al., 2006). It was found that Pietrain pigs, which are recognized as leaner with a higher concentration of protein and lower of fat in the carcass (Raj et al., 2010), had a significantly lower content of total saturated fatty acids than the other breeds. Pietrain pigs are very lean and it was shown by Kouba et al. (1999) and Wood et al. (2004) that the proportion of linoleic acid is higher in lean than in fatter pigs, which explains the highest concentration of C18:2 n-6 in all studied tissues of Pietrain pigs noted by us. Since de novo synthesis of fatty acids is lower in leaner breeds, therefore decreased endogenous fatty acids result in less dilution of exogenous linoleic acid (Girard et al., 1988). On the other hand, it should also be pointed out that linoleic acid cannot be synthesized in vivo in pigs and, therefore, its content reflects dietary intake and bioavailability from feed (Buckley et al., 1995).

The two studied Polish breeds did not differ substantially from Duroc pigs and the only differences concerned the MUFA content in both adipose tissues; these contents were higher in PLW. In fact, among the studied breeds, the MUFA content in abdominal fat was the highest in PLW. On the other hand, the PUFA content in fat tissues was the lowest in PLW, however, the differences were not significant.

From a nutritional point of view, pork is an important source of oleic and essential n-6 and n-3 fatty acids, with their well-known influence on human health (Tribole, 2006). C18:1 n-9 was identified in all analysed samples, and its content varied from $31.96 \%$ to $40.08 \%$, depending on the breed and tissue. Abdominal fat was characterized by a significantly lower percentage of C18:1 n-9, whereas intramuscular fat had the highest content. Since oleic acid is a major component of MUFA in pigs, the trend for differences in total MUFA content is correlated with changes in C18:1 n-9 levels. The ratio of total PUFA to SFA has been widely used as a dietary lipid quality in relation to atherogenicity (Ulbricht and Southgate, 1991). Although stearic acid is considered a neutral fatty acid, excessive intake of 
SFA has been considered as the main factor for cancer and coronary heart disease (Webb and O'Neill, 2008). The PUFA:SFA ratio is recommended to be above 0.4. In all of the analysed breeds, however, this ratio in intramuscular and visceral fat was below 0.4, averaging 0.29 and 0.27 , respectively. The PUFA:SFA ratio in the backfat of Pietrain pigs was 0.47 and was higher than in the other breeds, where the average was 0.35 . The risk of coronary heart disease is also correlated with the ratio of n-6 and n-3 polyunsaturated fatty acids (Enser, 2001), and the recommendation for this ratio is that it be under 4. Our results showed that the n-6-to-n-3 ratio in all breeds was relatively high compared with the recommended values and exceeded 5; only in the abdominal and subcutaneous fat tissues of Polish Landrace the average ratio was 3.99 and 3.98, respectively. Lee et al. (2010) showed that Berkshire pigs had a very high average ratio (16.57), which was associated with a high content of C18:2 n-6. Contrary to our results Enser et al. (1996) observed more C18:1n-9 in adipose tissue than in muscle, and similar levels of C18:2 n-6 in these two tissues. The degree of unsaturation of fatty acids is shown as the sum of MUFA and PUFA contents. This sum is strongly associated with the possibility of oxidation, rancidity, softness, and texture of the fat as the number of double bonds in fatty acids increases and the melting point and oxidative stability of these acids decline (Wood et al., 1999). Nevertheless, Raj et al. (2010), who compared pure breeds of Belgian Landrace, Duroc, Hampshire, and Pietrain, reported that greater saturation was observed in intramuscular fat rather than in backfat.

Linear discriminant analysis (LDA), which was used in our research to differentiate tissues and breeds based on fatty acid profiles, belongs to supervised learning techniques. In contrast to unsupervised methods like PCA, apart from visualization of samples LDA also enables classification and prediction of unknown samples. LDA and other classification techniques, such as Kohonen self-organizing maps, counter-propagation artificial neural networks have found many applications in food authenticity research and everywhere where sample classification is needed (i.e., regional classification, botanical origin, different technologies) (Cserhàti, 2008). LDA has also found application in authentication studies of fattening Iberian pigs based on volatile compounds from subcutaneous fat (Narvàes-Rivas et al., 2011). LDA used for volatile compounds data obtained by an electronic nose also enabled differentiation of products derived from Iberian breed pigs according to their feeding regime (Gonzàlez-Martin et al., 2000). The results obtained in our study indicate that a chemometric approach used for fatty acid analysis enables differentiation of tissues and breeds, which can be used for their classification or prediction of unknowns in traceability and authenticity studies. This aspect is not usually pointed out in papers on fatty acid analysis in different breeds. 
Several authors have reported dependencies between fatness traits and PUFA in muscle and adipose tissues. Wood et al. (2004) observed that pig breeds with thinner backfat (Duroc and Large White) had higher concentrations of C18:2 n-6 in the Longissimus dorsi muscle compared with Berkshire with thicker backfat. Kouba et al. (2003) showed that deposition of subcutaneous fat with age is accompanied by a decreasing content of C18:2 n-6 in the Longissimus dorsi muscle. Comparison of pig carcasses showed that an increase in backfat thickness also correlates with lower levels of C18:2 n-6 and C18:3 n-3 in subcutaneous adipose tissue. (Wood et al., 1989). On the other hand, our results show that abdominal fat weight can also be another marker of PUFA content in Longissimus dorsi and backfat.

\section{CONCLUSIONS}

The observed between-breed variability of the fatty acid (FA) profile confirmed earlier observations that the carcass of Pietrain pigs has the lowest saturated fatty acid and the highest unsaturated fatty acid contents. Our results indicate that differences between the two major Polish breeds (Polish Large White; PLW) and Polish Landrace and Duroc pigs are not as substantial. It should be pointed out, however, that among the studied breeds, the monosaturated fatty acid (MUFA) content in subcutaneous fat was the highest in PLW and, in addition, the MUFA content was higher in the subcutaneous fat of PLW than in Duroc pigs. Moreover, the FA profile facilitated distinguishing the studied breeds by linear discriminat analysis, with an overall prediction ability of 89.8 . Finally, our study revealed a negative correlation between abdominal fat weight and percentage of polyunsaturated fatty acids in all three analysed tissues, and thus we assume that it is another factor, apart from leanness, that influences the profile of unsaturated FA in the pig carcass.

\section{REFERENCES}

Buckley D.J., Morrisey P.A., Gray J.I., 1995. Influence of dietary vitamin E on the oxidative stability and quality of pig meat. J. Anim. Sci. 73, 3122-3130

Cserhàti T., 2008. Multivariate Methods in Chromatography. A Practical Guide. Wiley, Chichester (UK)

Corino C., Musella M., Mourot J., 2008. Influence of extruded linseed on growth, carcass composition, and meat quality of slaughtered pigs at one hundred ten and one hundred sixty kilograms of live weight. J. Anim. Sci. 86, 1850-1860

Enser M., 2001. The role of fats in human nutrition. In Oils and fats. In: B. Rossell (Editor). Animal Carcass Fats. Leatherhead Publishing. Leatherhead, Surrey (UK), pp. 77-122 
Enser M., Hallet K., Hewitt B., Fursey G.A.J., Wood J.D., 1996. Fatty acid contents and composition of English beef, lamb and pork at retail. Meat Sci. 42, 443-456

Folch J.M., Lees M., Stanley G.H.S., 1957. A simple method for the isolation and purification of lipids from animal tissues. J. Biol. Chem. 226, 497-509

Girard J.P., Bout J., Salort D., 1988. Lipides et qualities des tissues adipeux et musculaires du porc, facteurs de variations. Journées Rech. Porcine 20, 255-278

Gonzalez-Martin I., Pérez-Pavón J.L., Gonzàlez-Pérez C., Hernàndez-Méndez J., Àlvarez-García N., 2000. Differentiation of products derived from Iberian breed swine by electronic olfactometry (electronic nose). Anal. Chim. Acta 424, 279-287

Kouba M., Bonneau M., Noblet J., 1999. Relative development of subcutaneous, intramuscular, and kidney fat in growing pigs with different body composition. J. Anim. Sci. 77, 622-629

Kouba M., Enser M., Whittington F.M., Nute G.R., Wood J.D., 2003. Effect of a high-linolenic acid diet on lipogenic enzyme activities, fatty acid composition, and meat quality in the growing pig. J. Anim. Sci. 81, 1967-1979

Kouba M., Mourot J., 2011. A review of nutritional effects on fat composition of animal products with special emphasis on n-3 polyunsaturated fatty acids. Biochimie 93, 13-17

Lee S.H., Choi Y.M., Choe J.H., Kim J.M., Hong K.C., Park H.C., Kim B.C., 2010. Association between polymorphisms of the heart fatty acid binding protein gene and intramuscular fat content, fatty acid composition, and meat quality in Berkshire breed. Meat Sci. 86, 794-800

Maw S.J., Fowler V.R., Hamilton M., Petchey A.M., 2003. Physical characteristics of pig fat and their relation to fatty acids composition. Meat Sci. 63, 185-190

Mieńkowska-Stępniewska K., Kulisiewicz J., Orzechowska B., Kamyczek M., Batorska M., 2006. Muscle lipids in Polish maternal and paternal breeds of pigs. Anim. Sci. Pap. Rep. 24, Suppl. $1,175-186$

Monziols M., Bonneau M., Davenel A., Kouba M., 2007. Comparison of the lipid content and fatty acid composition of intermuscular and subcutaneous adipose tissues in pig carcasses. Meat Sci. $76,54-60$

Narvàez-Rivas M., Pablos F., Jurado J.M., León-Camacho M., 2011. Authentication of fattening diet of Iberian pigs according to their volatile compounds profile from raw subcutaneous fat. Anal. Bioanal. Chem. 399, 2115-2122

Niedźwiedzka K.M., Kowalczyk J., Czauderna M., 2008. Influence of selenate and linseed oil on fatty-acid and amino-acid profiles in the liver, muscles, fat tissues and blood plasma of sheep.

J. Anim. Feed Sci. 17, 328-343

Ntawubizi M., Colman E., Janssens S., Raes K., Buys N., De Smet S., 2010. Genetic parameters for intramuscular fatty acid composition and metabolism in pigs. J. Anim. Sci. 88, 1286-1294

Peinado J., Serrano M.P., Nieto M., Sánchez J., Medel P., Mateos G.G., 2012. The effects of gender and castration of females on performance and carcass and meat quality of heavy pigs destined to the dry-cured industry. Meat Sci. 90, 715-720

Quintanilla R., Pena R.N., Gallardo D., Cánovas A., Ramírez O., Díaz I., Noguera J.L., Amills M., 2011. Porcine intramuscular fat content and composition are regulated by quantitative trait loci with muscle-specific effects. J. Anim. Sci. 89, 2963-2971

Raj S., Skiba G., Weremko D., Fandrejewski H., Migdał W., Borowiec F., Poławska E., 2010. The relationship between the chemical composition of the carcass and the fatty acid composition of intramuscular fat and backfat of several pig breeds slaughtered at different weights. Meat Sci. $86,324-330$

Sellier P., Maignel L., Bidanel J.P., 2010. Genetic parameters for tissue and fatty acid composition of backfat, perirenal fat and longissimus muscle in Large White and Landrace pigs. Animal 4, 497-504 
Switonski M., Stachowiak M., Cieslak J., Bartz M., Grzes M., 2010. Genetics of fat tissue accumulation in pigs - a comparative approach. J. Appl. Genet. 51, 153-168

Tribole E.F., 2006. Excess omega-6 fats thwart health benefits from omega-3 fats. Brit. Med. J. 332, $752-760$

Uemoto Y., Soma Y., Sato S., Ishida M., Shibata T., Kadowaki H., Kobayashi E., Suzuki K., 2012. Genome-wide mapping for fatty acid composition and melting point of fat in a purebred Duroc pig population. Anim. Genet. 43, 27-34

Ulbricht T.L.V., Southgate D.A.T., 1991. Coronary heart disease: Seven dietary factors. Lancet 338, 985-992

Webb E.C., O’Neill H.A., 2008. The animal fat paradox and meat quality. Meat Sci. 80, 28-36

Wood J.D., Esner M., Fisher A.V., Nute G.R., Richardson R.I., Sheard P.R., 1999. Manipulating meat quality and composition. Proc. Nutr. Soc. 58, 363-370

Wood J.D., Enser M., Fisher A.V., Nute G.R., Sheard P.R., Richardson R.I., Hughes S.I., Whittington F.M., 2008. Fat deposition, fatty acid composition and meat quality: A review. Meat Sci. 78, 343-358

Wood J.D., Enser M., Whittington F.M., Moncrieff C.B., Kempster A.J., 1989. Backfat composition in pigs: differences between fat thickness groups and sexes. Livest. Prod. Sci. 22, 351-362

Wood J.D., Lister D., 1973. The fatty acid and phospholipid composition of Longissimus dorsi muscle from Pietrain and Large White pigs. J. Sci. Food Agr. 24, 1449-1456

Wood J.D., Nute G.R., Richardson R.I., Whittington F.M., Southwood O., Plastow G., Mansbridge R., Da Costa N., Chang K.C., 2004. Effects of breed, diet and muscle on fat deposition and eating quality in pigs. Meat Sci. 67, 652-667

Wood J.D., Richardson R.I., Nute G.R., Fisher A.V., Campo M.M., Kasapidou E., Sheard P.R., Enser M., 2003. Effect of fatty acids on meat quality: a review. Meat Sci. 66, 21-32

Zhang S., Knight T.J., Stadler K.J., Goodwin R.N., Lonergan S.M., Beitz D.C., 2007. Effect of breed, sex, and halothane genotype on fatty acid composition of pork longissimus muscle. J. Anim. Sci. 85, 583-591 